\title{
Study on the derived based catalysts from Theobroma cacao pod husks for the conversion of beef tallow blend with waste used vegetable oil for fatty acid ethyl ester synthesis: burnt, submerged fermented, calcination, hybrid design, catalyst refining and reusability
}

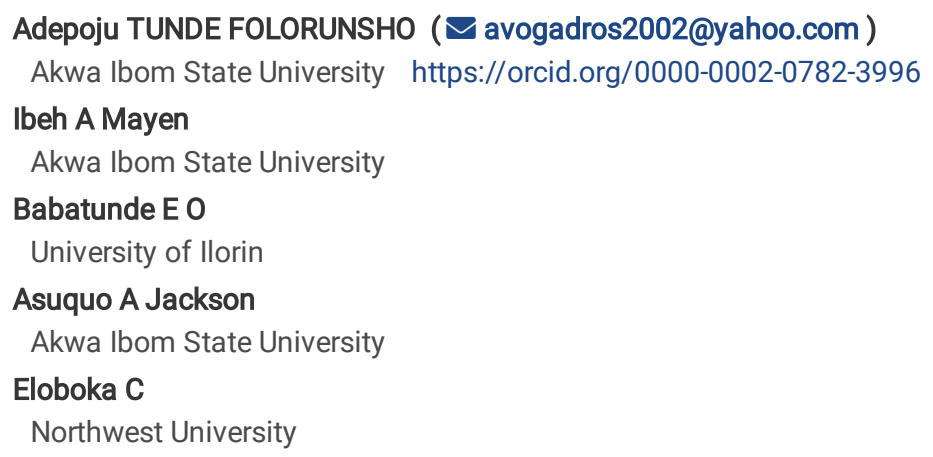




\section{Abstract}

Billions of dollars paid by industries on catalysts used as feedstocks to obtain their end products are increasing at a geometrical rate, the report revealed that the global marketplace price of catalysts stood at USD 26.1 billion in 2019 , and is anticipated to increase by $4 \%$ in 2020 , and $4.5 \%$ progress rate in 2025. To salvage the world from extravagance spending, there is an urgent need for biomass wastes consideration and utilization. In this paper, three novel CaO-based catalysts derived from Theobroma cacao pod husks were tested based on efficacy for the production of biodiesel (fatty acid ethyl ester: FAEE) from the blend of beef tallow-waste use oil in the ratio of 5:95 $\left(\mathrm{BTO}_{5}\right), 10: 90\left(\mathrm{BTO}_{10}\right), 15: 85\left(\mathrm{BTO}_{15}\right), 20: 80\left(\mathrm{BTO}_{20}\right), \ldots . .$. , 95:5 $\left(\mathrm{BTO}_{95}\right)$, respectively. Process optimization of the transesterification reaction was carried out using a hybrid design to determine the effects of catalyst on the FAEE yield. The efficiencies of the catalyst were tested via the refining and reusability test. Results revealed the oil blend ratio of $\mathrm{BTO}_{60}: \mathrm{WUO}_{40}$ sufficiently produced low viscous oil that was easily converted to biodiesel. Catalysts' characterization revealed the three catalysts produced high CaO-based of $68.20,81.46$, and 87.65 (wt.\%), which accounted for the high yield of FAEEs.

Mathematical optimization showed that the catalyst amount (F-value between 14159.69-3063.24 with P-value between 0.0053-0.0115), played the most significant role in oil conversion to biodiesel among the constraint factors considered (reaction time, catalyst amount, reaction temperature, and EtOH/OMR).

Based on Box-Cox transformation, the values of the lambda obtained indicated a normal data results with an inverse function of $\mathrm{Y}^{2}$ and $\mathrm{Y}^{3}$ and normal function of $\mathrm{Y}^{3}$ for polynomial model accuracy. Optimum validated FAEEs yields of 92.81, 93.02, and 99.64 (\%wt.), respectively, with high $\mathrm{R}^{2}$. The qualities of the FAEEs were within the standard specification and the produced catalysts can serve as feedstocks for industrial application.

\section{Introduction}

Many chemical reactions involved the use of one or more catalysts for reaction to reach completion. The type of catalyst used in a particular reaction depends solely on the reaction conditions and the nature of reactants involved. Although catalysts are not to be consumed in the reaction, its presence speeds up or limits reaction rate, and itself recover at the end of product formation. Nowadays, industries such as pharmaceuticals, polymers, petroleum, electronic, environmental treatment, chemical, and agrochemical industries employ the use of catalysts to achieve the end products. Also, the use of catalysts occupies an important place in academic research. A recent report revealed that the worldwide marketplace price of catalysts stood at USD 26.1 billion in 2019, and is anticipated to increase by $4 \%$ in 2020 , and $4.5 \%$ progress rate in 2025 according to Compound Annual Growth Rate (CAGR). This makes it a value-added income for the financial sustainability of all nations if biomass waste can be employed. However, catalysts are primarily divided into four categories; homogeneous catalyst, heterogeneous catalyst, heterogenized-homogeneous catalysis, and biocatalysts.

Homogeneous catalysis involved the operation of the mixture in the same phase, the possible reactant and the catalyst exhibit a high uniform phase due to high reactivity and selectivity. Most oxidation, carbonylation, hydrogenation, esterification, and hydrocyanation are homogeneous catalysis in reaction. However, this nature of catalyst usage comes with its shortcoming, this includes recoverability problem, highly toxic, and high cost, especially in esterification (bio-fuel production) case.

Heterogeneous catalysis, on the other hand, involved the mixture that exists in different phases; the catalyst usually solid support or bulk form does not dissolve in the reactant, yet exhibit high reactivity. The advantages include ease of recoverability and reused, non-toxic, and of low cost. These have made many industries such as hydrocarbon produced company (Fischer process), ammonia synthesis company (Haber-Bocsch process), sulphuric acid company (Contact process), soap making company (Saponification process), and petroleum company (transesterification process) to adhere to the use of this catalysts, apart from these advantages, heterogeneous catalysts produce in smaller particle size increase its activity due to surface phenomenon. The smaller the particles size the larger the surface area of catalysts during the reaction.

Heterogenized-homogeneous catalysis is the mixture of the heterogeneous and homogeneous catalysts together. The homogeneous catalyst is embedded onto the solid supports to prepare the heterogenic analogy. However, these types of catalysts are difficult to produce due to complexity, less selectivity, reactivity, and covalent bonding between the polymer chain and the surface atoms (grafting).

Biocatalysts are usually referred to as enzymes or ribozymes catalysts obtained from plants, microbes, or Goat tissue, which are used to catalyst reaction that takes place outside the living cells. This type of catalyst is on high industrial usage and has been considered an alternative to most industrial conventional catalysts due to the advantages such as mild reaction conditions, high selectivity, high efficiency, and non-toxic. Companies such as, dairy, baking, detergent, leather, textile, and biofuel utilized this catalyst for their production. Its major drawbacks are in-ability to convert a cellular catalyst into a bioprocess, difficulty in recoverability (brewing process) sustainability in harsh environmental conditions during culture (high temperature, extreme $\mathrm{pH}$, high salt concentrations, organic solvent), instability in aqueous media (protein), cofactor dependability (non-protein chemical compound), possibility of an allergic reaction, and inactivation through inhibition (Dizge et al., 2009)[1].

Among these catalysts, a heterogeneous catalyst is a solid catalyst of calcium-based compound usually prepared from solid wastes and used as a base catalyst in conversion of oil to biodiesel due to the above-mentioned advantages (Milan et al., 2016)[2]. Biodiesel is a bio-renewable, eco-friendly, non-toxic, and sustainable alternative fuel derived from the synthesis of vegetable oil or fat. In the past and also present, reports on solid based 
developed from solid wastes as heterogeneous catalysts and applied it to the synthesis of biodiesel from vegetable oil. Vadery et al. (2014)[3] synthesized biodiesel from Jatropha oil through methanolysis of a developed based catalyst from coconut husk ash, while Bazargan et al. (2015) [4] adopted the used of palm kernel shell gasification as a heterogeneous biocatalyst for biodiesel synthesis. Chouhan et al. (2013)[5] converted Jatropha curcus oil to biodiesel through the help of Lemna perpusila Torrey ash, but, Razaei et al. (2013) [6]used waste mussel shell as a catalyst to synthesized biodiesel. The work of Ikbal et al. (2018) [7] reported the practice of discarded snail shells as a heterogeneous catalyst for the synthesis of biodiesel from soybean oil, while in 2019, Subramaniapillai [8] and co used Donax delltoides shell as heterogeneous catalyst. The use of pearl spar as a heterogeneous catalyst was employed in the study reported by Adepoju et al. (2018)[9], while in another work, Betiku et al. (2015)[10] developed heterogeneous catalyst from plantain peel, applied it to biodiesel synthesis from yellow oleander. The study conducted in another work by Betiku et al. (2017)[11] reported the use of heterogeneous catalyst developed from cocoa pod husks, while Nath et al. (2019)[12] developed heterogeneous catalyst from waste Brassica nigra plant for biodiesel production. In the work of Balajii et al. (2020)[13], the heterogeneous catalyst was made from the Banana peduncle, meanwhile, Minakshi et al. (2020)[14] used Carica papaya stem as a bio-based catalyst. Further study by Hadiyanto et al. (2016)[15] utilized Anadara granosa as a heterogeneous CaO-based catalyst, but, Trisupakitti et al. (2019) [16] used golden apple cherry snail as a heterogeneous catalyst to synthesized biodiesel from the vegetable. Falowo et al. (2020)[17] developed a new base catalyst from a combination of biomass wastes. All these reports developed catalysts from mixture or single solid wastes, and applied it to the synthesis of biodiesel from vegetable oil or its blend, except in the work of Adepoju, (2020) [18] where two derived base catalysts were tested on the synthesized biodiesel from the blended oil.

Therefore, to cover the gap between the efficiency of the developed catalysts derived from single or the mixture of solid wastes, and to introduce a novel blend ratio through the BT05, BT010, BT015,........., BT095 in an interval of 5 between the Beef Tallow Oil (BTO) and Waste Used Vegetable Oil (WUVO) for process industry (bio-fuel or margarine), this study developed three CaO-based catalysts from a burnt Theobroma cacao pod husk (BTCPH), calcined Theobroma cacao pod husk (CTCPH), and submerged fermented calcined Theobroma cacao pod husk (SFCTCPH), applied each for the synthesis of biodiesel from the blended of the oil obtained from Beef tallow-vegetable used oil. The catalysts prepared were characterized via Scanning Electron Microscopy (SEM), Energy Dispersive Spectroscopy (EDS), X-ray diffraction analysis (XRD), Fourier transforms infrared spectroscopy (FTIR), BET adsorption analysis, and Hammett indicator. Process modeling and optimization of biodiesel synthesis was carried out by considering five levels-four factors (reaction time: $\mathrm{X}_{1}$, reaction temperature: $\mathrm{X}_{2}$, catalyst amount: $\mathrm{X}_{3}$, and ethanol to oil molar ratio (EtOH/OMR): $\mathrm{X}_{4}$ ) via Box Behnken Experimental Design (BBED). Catalysts regeneration and reusability were carried out, and the suitability of the biodiesel in an internal combustion engine was established by determining the physicochemical properties.

\section{Materials And Methods}

\subsection{Materials}

WUVO was gotten from University cafeteria, Akwa Ibom State University; beef tallow was obtained from a slaughterhouse in Ikot Akpaden, Akwa Ibom State, Nigeria. The WUVO was thermally heated in a reactor pot at $120^{\circ} \mathrm{C}$ placed on the temperature regulated hot plate for 25 min, and allowed to at $27-28{ }^{\circ} \mathrm{C}$, and then sieved to eliminate impurities. The filtered oil made cleaned was kept in a 10-litre drum tightly covered for further used. Meanwhile, the beef tallow was thoroughly washed in an open vessel with half litre of $1.0 \mathrm{~N}$ disodium tricarbonate, and stirred for 15 min via mechanical mean. The resulting mix was centrifuged at 3000 revolution per minute for $15 \mathrm{~min}$ at a temperature of $30^{\circ} \mathrm{C}$ using a polypropylene tube.

The supernatant was separated by filtration, and $40 \mathrm{~g}$ of anhydrous disodium sulphate was added, stirred for $8 \mathrm{~min}$, and was re-centrifuged again for $6 \mathrm{~min}$ at a temperature of $25^{\circ} \mathrm{C}$ (Adepoju, 2020)[18]. The purified beef tallow oil (PBTO) acquired was saved in a tightly covered container for further use.

Cocoa pod husk was obtained from Cocoa processing factory in Ondo State, Nigeria. The pod husk was cleaned by washing with ionized water, and was decanted, kept overnight to allow proper draining. The drained cleaned cocoa pod husk was separated into three-samples: Sample A was burnt in the open air until its completely formed ash; the ash was separated into smaller unit sizes $(0.30 \mathrm{~mm})$ by sifting, labelled as BTCPH. Sample B was milled into powder, divided into a smaller unit size of $0.3 \mathrm{~mm}$ by mesh sieve, and then calcined at $750{ }^{\circ} \mathrm{C}$ for $4 \mathrm{~h}$ in a muffle furnace. Sample $\mathrm{C}$ was fermented in distilled water anaerobically (submerged) for 10 days, and then the fermented sample was separated from fermented water by decantation, dried in an oven at $120^{\circ} \mathrm{C}$ until a constant weight was achieved (bone dried). The dried fermented sample was milled and sieved into powder of $0.33 \mathrm{~mm}$ particle size before calcined at $750^{\circ} \mathrm{C}$ for $4 \mathrm{~h}$ in a furnace. Both samples B (CTCPH) and C (SFCTCPH) after calcination were left in the furnace for $24 \mathrm{~h}$ for proper cooling, and then placed in cleaned containers as well as BTCPH for further characterization to determine their potential as a heterogeneous catalyst for industrial application (biofuel production).

All chemicals used in this study were of analytical graded and need no further purifications, and were supplied by Sigma Aldrich.

\subsection{Catalysts calcination and characterization}

Samples BTCPH, CTCPH, and SFCTCPH were characterized by SEM to study the high spatial resolution (surface morphology) of the samples, XRD fortified thru Ká and Cu radiation source, enhanced at $20 \mathrm{~mA}$ and $40 \mathrm{kV}$, to institute the angular scanning electron implemented in the range of $10^{\circ}$ $<2 \theta<80^{\circ}$ at speed of $2.5^{\circ} \mathrm{C} \mathrm{min}-1$ and to confirm the elemental analysis of the samples and the quantitative structure of the samples. FTIR was used 
to check the presence of functional group and validate the presence of characteristic absorption bands of major elements present within the crystals powder structures. BET isothermal adsorption and Hammett indicator was used to establish the pore volume, the surface area, the basic density site, and the total basic density.

\subsection{Oil blend and its physicochemical properties}

For proper oil mixed, it is necessary to know the synergy behind the oil mixed, a probability guesses mixed adopted in reported studies might result in fuel-engine problems. The key factors to be considered in mixing oil are the oil low viscosity, high volatility, and moderate acid value. Since there is no single report on the blend/mix ratio of BTO and WUVO, therefore this study adopted the following blend/mix ratios for BTO:WUVO in volumetric ratios as; 5:95 $\left(\mathrm{BTO}_{5}\right), 10: 90\left(\mathrm{BTO}_{10}\right), 15: 85\left(\mathrm{BTO}_{15}\right), 20: 80\left(\mathrm{BTO}_{20}\right), 25: 75\left(\mathrm{BTO}_{25}\right), 30: 70\left(\mathrm{BTO}_{30}\right), 35: 65\left(\mathrm{BTO} \mathrm{O}_{35}\right), 40: 60\left(\mathrm{BTO} \mathrm{H}_{40}\right), 45: 55\left(\mathrm{BTO}{ }_{45}\right), 50: 50$ $\left(\mathrm{BTO}_{50}\right), 55: 45\left(\mathrm{BTO}_{55}\right), 60: 40\left(\mathrm{BTO}_{60}\right), 65: 35\left(\mathrm{BTO}_{65}\right), 70: 30\left(\mathrm{BTO}_{70}\right), 75: 35\left(\mathrm{BTO}_{75}\right), 80: 20\left(\mathrm{BTO}_{80}\right), 85: 15\left(\mathrm{BTO} \mathrm{C}_{85}\right)$, , $90: 10(\mathrm{BTO} 90), 95: 5(\mathrm{BTO} 95)$, respectively. These ratios were chosen to ascertain oil with low viscous, high volatility, and low acid value that enhanced higher biodiesel yield using the derived CaO-based heterogeneous catalysts. 5:95 $\left(\mathrm{BTO}_{5}\right)$ is an abbreviation for $5 \mathrm{ml}$ of BTO and $95 \mathrm{ml}$ of WUVO.

The blended oil in different ratios was properly mixed by heating at $35^{\circ} \mathrm{C}$ on a hot plate for easy miscibility owing to the uncertainty in the nature fat. The viscosity, the acid value, and the specific gravity of the resultant mix were examined. The mix with low acid value, low specific gravity, and low viscosity was used for methylester (biodiesel) production. Additional properties such as iodine value, saponification, peroxide, cetane number, moisture content, etc. of the mixed oil were further determined via the official standard methods (AOAC 1997 and AOAC 1990)[19, 20].

\subsection{Biodiesel production}

Production of biodiesel was carried out through the use of derived heterogeneous based CaO-catalyst synthesized from samples. The reaction process took placed in a $1000 \mathrm{ml}$ reactor with three-necked, $200 \mathrm{ml}$ of the oil mixed was first heated at $100{ }^{\circ} \mathrm{C}$ for 60 min using a hot plate equipped with a magnetic stirrer. 2.5 (wt.\%) of $\mathrm{CaO}$ catalyst was measured in a $250 \mathrm{ml}$ dried-cleaned flask, and $50 \mathrm{ml}$ of ethanol was measured and added to the ethanol flask to achieved EtOH/OMR of 1:4. The mix was positioned on a shaker for $15 \mathrm{~min}$, and then introduced to the heated oil in the reactor. The resulting dilution displayed two separated layers which contained the ethanol-catalyst layer and the oil layer, then the stirrer was introduced, and the reaction process was observed at $70^{\circ} \mathrm{C}$ for $65 \mathrm{~min}$.

At the end of reaction process, the non-soluble CaO-catalyst was removed by decanting, and the resultant product (ethanol-based-diesel) was distinguished through density separation. The biodiesel (fatty acid ethyl ester: FFEE) with leached catalyst was separated by washing with warm mixture of $1.0 \mathrm{~g} \mathrm{NaCO}_{3}$ and $20 \mathrm{ml}$ methanol. The washed mixed was separated by filtration, and the filtrate-diesel was washed with ionized water, and separated via gravity settling. The water wet-diesel was dried over anhydrous sodium sulphate $\left(\mathrm{Na}_{2} \mathrm{SO}_{4}\right)$, and was separated by liquid-solid separation (decantation) to obtain the pure FAEE as liquid. The solid residual catalyst purified and reused. The step by step reaction process was conducted based on number of experimental runs generated by design expert.

\subsection{Experimental design for FAEE}

Experimental design software like Box Behnken Design (BBD), Central Composite Design (CCD), Factorial Design (FD), as well as Tanquchi design (TD) contains a lack of fits in the model analysis. Lack of fits only exist when the experimental design is poor, a poor model of the data, or poor choice of variables. This then results in high residual/error value, experimental replications, and a high number of experimental runs (between $28-45$ runs) when considering four-variable-five level-factors. Therefore, to avoid these problems, considering four factors (reaction time: $X_{1}$, catalyst amount: $X_{2}$, reaction temperature: $X_{3}$, and ethanol/oil molar ratio (EtOH/OMR): $X_{4}$ ), a Hybrid Design (HD) with a minimal point design for $3,4,6$, and 7 factors with 5 level levels each was employed. This design has no replication to avoid time wastage; it has no lack of fits because the residual or error values are so small $\left(10^{-10}\right)$ due to better experimental design, and a low number of experimental runs (four factors produced 16 runs) to avoid repetitions. These rotatable designs are better than BBD, CCD, FD, and TD, but are highly sensitive to outlier (missing data). Table 1 displayed the four- five level- four variable- factors, the units, and the symbol used for the HD design.

Table 1: Five level- four variable- factors experimental for FAEE

\begin{tabular}{lllllll}
\hline Variables & \multirow{2}{*}{ Units } & Symbol & \multicolumn{6}{c}{ Levels } \\
\cline { 3 - 7 } & & -2 & -1 & 0 & 1 & 2 \\
\hline Reaction time & $(\mathrm{min})$ & 60 & 65 & 70 & 75 & 80 \\
Catalyst amount & $(\mathrm{wt} . \%)$ & 1.5 & 2.0 & 2.5 & 3.0 & 3.5 \\
Reaction temp. & $\left({ }^{\circ} \mathrm{C}\right)$ & 60 & 65 & 70 & 75 & 80 \\
EtOH/OMR & $(\mathrm{ml} / \mathrm{ml})$ & 4 & 5 & 6 & 7 & 8 \\
\hline
\end{tabular}

\subsection{Optimization analysis of FAEE}

The experimental results were used for the process optimization analysis of the FAEE production. The response variable was the FAEE yield, the input variables were the factors at five levels evaluated by mean of fit summary. In the second-order model, the effects of variable significant and preferred 
terms were appraised by model effects. The ANOVA analysis (Analysis of Variance) was adapted to elucidate the results while diagnostic was used to estimate the fit of the model, and model transformation, the graphical plots were used to interpret and evaluates the model. The p-value called the probability value, the $\mathrm{f}$-value called the factor value, the df known as degree of freedom, and the VIF called the variance inflation factor, were used for model significance. The regression parameters such as the coefficient of determination: the predicted coefficient of determination, the adjusted coefficient of determination: and the adequate precision: Adeq. Prec., respectively, were used to check the model aptness.

Tri-dimensional space (three-dimensional plots) was used as a geometric setting to express the relationship between three variables (two factors and FAEE yield), while the second-order differential equation that further elucidates the connection between FAEE yield and the four factors is expressed arithmetically as Eq. (1). (see Supplementary Files)

\subsection{Catalyst purification and reusability}

The recovered catalysts were tried for its effectiveness by carried out the reusability tests however the catalyst was first refined. Purification stage was carried out by the method used by Adepoju et al. (2020a)[21] with modifications as; the obtained catalyst was washed with an alcohol to eliminate the contaminate adhere at the catalyst interface as a result of transesterification processes. The catalyst purified with alcohol was centrifuged at $3500 \mathrm{rpm}$ using an inbuilt heating vacuum centrifuge, and separated by decantation. The wet catalyst was dried in oven at $80{ }^{\circ} \mathrm{C}$ for 60 min so as to make free of the alcohol before cooled temperature of $27^{\circ} \mathrm{C}$ and then reused.

\subsection{Properties of FAEE}

Properties of the FAEE such as density, viscosity, moisture content, mean molecular mass, acid, saponification, iodine, peroxide, higher heating value, cetane number, API gravity, and diesel index were determined so as to determine its aptness as an substitute for conventional fuel used in an diesel engine, via AOAC, 1997[19]. The qualities were likened with ASTM D6751 [22] and EN 14214 [23] recommended standard.

\section{Results And Discussion}

\subsection{Physicochemical properties of the blended oil}

Presented in Table 2 are the datasets of the physicochemical qualities of the blended oil in a different ratio. Observation from the table indicated that the blended oil in the different ratio has the same percentage moisture content of $0.02 \%$, all other blends have different values, except for the $\mathrm{BTO}_{50}$ and $\mathrm{BTO}_{85}$ having the same viscosity $(23.10 \mathrm{~mm} / \mathrm{s})$, and $\mathrm{BTO}_{25}, \mathrm{BTO}_{30}$, and $\mathrm{BTO}_{75}$ having the same Saponification value (185.00 mg KOH/g oil).

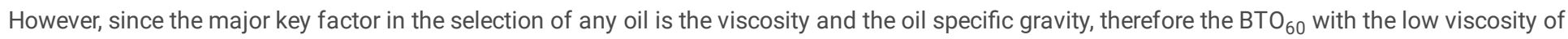
22. $30 \mathrm{~mm}^{2} / \mathrm{s}$ and a specific gravity of 0.890 were selected as blended oil for FAEE production. This blended oil produced lighter oil with low acid value and high API gravity (Adepoju, 2020b)[24].

Table 2: Results of physicochemical properties of the oil blend 


\begin{tabular}{|c|c|c|c|c|c|c|c|}
\hline Blends & & & & Physicochemical P & roperties & & \\
\hline Ratio (BTO: WUVO) & MC (\%) & SG & $\mathrm{V} @ 40^{\circ} \mathrm{C}\left(\mathrm{mm}^{2} / \mathrm{s}\right)$ & $\mathrm{AV}$ (mgKOH/g oil) & SV (mg KOH/g oil) & IV (meq $\mathrm{O}_{2} / \mathrm{kg}$ oil) & API g \\
\hline $\mathrm{BTO}_{5}$ & 0.020 & 0.916 & 26.00 & 0.345 & 194 & 60.22 & 22.98 \\
\hline $\mathrm{BTO}_{10}$ & 0.020 & 0.914 & 25.80 & 0.332 & 192 & 60.18 & 23.31 \\
\hline $\mathrm{BTO}_{15}$ & 0.020 & 0.911 & 25.40 & 0.310 & 190 & 60.10 & 23.82 \\
\hline $\mathrm{BTO}_{20}$ & 0.020 & 0.912 & 24.90 & 0.303 & 189 & 60.03 & 23.65 \\
\hline $\mathrm{BTO}_{25}$ & 0.020 & 0.908 & 24.87 & 0.294 & 185 & 60.00 & 24.34 \\
\hline $\mathrm{BTO}_{30}$ & 0.020 & 0.910 & 24.60 & 0.296 & 185 & 59.86 & 23.99 \\
\hline $\mathrm{BTO}_{35}$ & 0.020 & 0.907 & 23.60 & 0.284 & 184 & 59.82 & 24.51 \\
\hline $\mathrm{BTO}_{40}$ & 0.020 & 0.905 & 23.50 & 0.283 & 186 & 59.80 & 24.85 \\
\hline $\mathrm{BTO}_{45}$ & 0.020 & 0.902 & 23.00 & 0.280 & 183 & 59.83 & 25.37 \\
\hline $\mathrm{BTO}_{50}$ & 0.020 & 0.904 & 23.10 & 0.262 & 185 & 59.56 & 25.03 \\
\hline $\mathrm{BTO}_{55}$ & 0.020 & 0.903 & 22.82 & 0.263 & 182 & 59.10 & 25.20 \\
\hline $\mathrm{BTO}_{60}$ & 0.020 & 0.890 & 22.30 & 0.249 & 180 & 58.88 & 27.49 \\
\hline $\mathrm{BTO}_{65}$ & 0.020 & 0.900 & 22.45 & 0.248 & 184 & 58.70 & 25.72 \\
\hline $\mathrm{BTO}_{70}$ & 0.020 & 0.902 & 22.52 & 0.252 & 186 & 58.60 & 25.37 \\
\hline $\mathrm{BTO}_{75}$ & 0.020 & 0.909 & 22.64 & 0.263 & 185 & 59.92 & 24.17 \\
\hline $\mathrm{BTO}_{80}$ & 0.020 & 0.911 & 22.86 & 0.272 & 188 & 59.94 & 23.82 \\
\hline $\mathrm{BTO}_{85}$ & 0.020 & 0.915 & 23.10 & 0.274 & 190 & 59.91 & 23.14 \\
\hline $\mathrm{BTO}_{90}$ & 0.020 & 0.913 & 22.94 & 0.276 & 191 & 59.70 & 23.48 \\
\hline $\mathrm{BTO}_{95}$ & 0.020 & 0.914 & 22.96 & 0.277 & 191 & 59.89 & 23.36 \\
\hline
\end{tabular}

$\mathrm{M}=$ Moisture content, $\mathrm{SG}=$ Specific gravity, $\mathrm{V}=$ Viscosity, $\mathrm{AV}=$ Acid value, $\mathrm{IV}=$ Iodine value, $\mathrm{PV}=$ Peroxide value, $\mathrm{SV}=\mathrm{Saponification}$ value, API $\mathrm{g}=\mathrm{API}$ gravity

\subsection{Characterization and analysis of catalysts}

\subsubsection{SEM analysis}

The morphological characteristic of the catalysts was carried out by SEM analysis. Fig 1(a, b, and c) displayed the results of SEM analysis of BTCPH, $\mathrm{CTCPH}$, and SFCTCPH at the same magnification of $500 \mathrm{x}$, but different structural outlook performed in $2 \theta$ diffraction with a peak from $20^{\circ}<2 \theta<80^{\circ}$ at speed of $2{ }^{\circ} \mathrm{C} / \mathrm{min}$. The image displayed by BTCPH indicated a highly crystal, cracked, less porous, and non-uniform shape structure whereas. This may be due to the burning process, as thermal burning in the open air, caused fusion and barrier for large surface area. The SEM image of CTCPH showed a uniform, highly porous with aggregated sizes and shape. This observation can be attributed to the surface fermentation process which makes it difficult for microorganisms to maintain homogeneous medium, thereby decreases the mineral content and the surface area of the cocoa pod husk powder. Observation from the morphological structure of SFCTCPH indicated a uniformly distributed structure with smaller sizes and shapes and a high surface area. This could be due to submerged fermentation which involves the growth of the microorganism in a homogeneous medium (inter-particle space and surface area) of the substrate and moisture content. However, it was observed that the release of the CaO from $\mathrm{CaCO}_{3}$ was complete at the calcination temperature of $750{ }^{\circ} \mathrm{C}$ (Betiku et al., 2017)[11].

\subsubsection{FTIR analysis}

The results of FTIR analysis of the burnt and calcined sample powder catalysts are displayed in Fig. 2(a-c). The spectral showed a sinusoidal waveform at different peaks confirming the effects of heat on the thermal degradation of the catalysts. The vivid descriptions of the wavelengths at different peaks for each catalyst which showed the stretches and the bending vibration of organic-inorganic functional groups present are presented in Table 4. The wavelength bands noticed between $693.3-913.2 \mathrm{~cm}^{-1}$ for CTCPH, and the bands between $752.9-913.2 \mathrm{~cm}^{-1}$ observed for SFCTCPH, and the wavelength stretches found in $\mathrm{BTCPH}$ of $879.7-1043.7 \mathrm{~cm}^{-1}$, specified the presence chlorocarbon $(\mathrm{C}-\mathrm{Cl}), \mathrm{O}=\mathrm{C}=\mathrm{O}$ bending vibration, nitrogen to carbon bond waging and twisting, and the presence of $\mathrm{CO}_{3}{ }^{2-}$ molecules at a lower temperature. 
The stretches range between 1036.2 - $1699.7 \mathrm{~cm}^{-1}$ observed in SFCTCPH, and $1032.5-1982.9 \mathrm{~cm}^{-1}$ noticed in CTCPH showed similar wavelength due to fermentation process involved, but the value of $1088.4-1379.1 \mathrm{~cm}^{-1}$ bands found in BTCPH confirmed the presence of sp ${ }^{3}$ of $\mathrm{C}-\mathrm{C}$ in alkane, $\mathrm{sp}^{2}$ delocalized electron of $\mathrm{C}=\mathrm{C}$ in alkene, $\mathrm{C}=\mathrm{N}$ of imines, and the bending vibration of $\mathrm{O}-\mathrm{Ca}-\mathrm{O}$ in calcium carbonate. Furthermore, $1420.1-1654.3 \mathrm{~cm}$ ${ }^{1}$ wavelength bands noticed in $\mathrm{cm}^{-1} \mathrm{BTCPH}$, the value range of $1893.5-2322.1 \mathrm{~cm}^{-1}$ observed in the wavelength bands of SFCTCPH, and the range between $1982.9-2050.0 \mathrm{~cm}^{-1}$ displayed by $\mathrm{CTCPH}$ indicated the presence of $\mathrm{C}=\mathrm{O}$ of ketone, $-\mathrm{CHO}$ of aldehyde, $\mathrm{C}=\mathrm{C}$ of ester, $\mathrm{C}-\mathrm{C}$ of alkyne/acetylene, $\mathrm{C}-\mathrm{N}$ of cyanogen, and $\mathrm{O}-\mathrm{H}$ of complex molecules. Further observation also indicated the presence of $\mathrm{O}-\mathrm{H}$ bending structure in alcohol and phenol, $\mathrm{O}=\mathrm{O}$ of dioxygen, and NO of sp were found in BTCPH, CTCPH, and SFCTCPH at wavelength bands of $1923.3-2974.5 \mathrm{~cm}^{-1}, 3623.0-3693.8 \mathrm{~cm}^{-1}$, and $3641.6-3753.4 \mathrm{~cm}^{-1}$, respectively, but the long stretches (> 3500) found in CTCPH and SFCTCPH showed the presence of amine and amide bonding structures (Adepoju et al., 2020b)[24]. This showed that fermentation increased the presence of functional groups and the surface area of the sample, but the calcined fermented submerge Theobroma cacao pod husk SFCTCPH showed more functional groups.

Table 4: FTIR sample spectrum analysis

\begin{tabular}{llll}
\hline SN & Wavelength $\left(\mathrm{cm}^{-1}\right)$ & Transmittance (\%) & Bonds and Functional groups \\
\hline BTCPH & & \\
\hline 1 & $879.7-1043.7$ & $58.079-29.767$ & C-Cl, $\mathrm{CO}_{3}{ }^{2-}, \mathrm{N}-\mathrm{H}$ waging and twisting, O=C=O bending vibration \\
2 & $1088.4-1379.1$ & $29.767-79.771$ & $\mathrm{C}-\mathrm{C}, \mathrm{C}=\mathrm{C}, \mathrm{C}=\mathrm{N}$, and O-Ca-O bending vibration \\
3 & $1420.1-1923.3$ & $82.562-98.503$ & $\mathrm{C}=\mathrm{O}, \mathrm{CHO}, \mathrm{CC}, \mathrm{CN}, \mathrm{O}=\mathrm{C}=\mathrm{O}$ of low energy, and O-H \\
4 & $2974.5-3336.0$ & $71.078-68.824$ & O-H bending structure, O=O, and NO \\
\hline CTCPH & & \\
\hline 1 & $693.3-913.2$ & $86.990-70.688$ & C-Cl, C-C. CO${ }_{3}^{2-}, \mathrm{N}-\mathrm{H}$ waging and twisting, O=C=O bending vibration \\
2 & $1032.5-1830.1$ & $57.307-97.256$ & C-C, C=C, C=N, and O-Ca-O bending vibration \\
3 & $1982.9-2050.0$ & $96.325-98.896$ & C=O, CHO, CC, CN, and O-H \\
4 & $3623.0-3693.8$ & $94.405-98.587$ & O-H bending structure, O=O, NO, Amine, and Amide \\
\hline SFCTCPH & & \\
\hline 1 & $752.9-913.2$ & $83.708-84.559$ & C-Cl, C-C. CO ${ }_{3}^{2-}, \mathrm{N}-\mathrm{H}$ waging and twisting, O=C=O bending vibration \\
2 & $1036.2-1699.7$ & $81.649-87.699$ & C-C, C=C, C=N, and O-Ca-O bending vibration \\
3 & $1893.5-2322.1$ & $92.902-90.263$ & C=O, CHO, CC, CN, and O-H \\
4 & $3641.6-3753.4$ & $75.796-88.068$ & O-H bending structure, O=O, NO, Amine, and Amide \\
\hline
\end{tabular}

\subsubsection{Brunauer-Emmett-Teller (BET) and XRD analysis}

Displayed in Table 5 are the results of the analysis of BET and XRD of the catalysts sample. A strong basic site $(176,188$, and 196$)$ was found in the catalysts which suggested that the produced catalyst are capable to be used as heterogeneous catalysts for FAEE production, as well as for other industrial applications. The basic site density does not depend on the pore volume of the catalysts but depends solely on the surface area of the catalysts. The higher the surface area, the lesser the basic site density, hence, the value of $176.00 \mu \mathrm{mole} / \mathrm{m}^{2}$ obtained for BTCPH, $170.91 \mu \mathrm{mole} / \mathrm{m}^{2}$ obtained for $\mathrm{CTCPH}$, and $178.18 \mu \mathrm{mole} / \mathrm{m}^{2}$ obtained for SFCTCPH. The results of XRD analysis showed that the total basic site was responsible for the high transformation of $\mathrm{CaCO}_{3}$ to $\mathrm{CaO}$. Despite the fact that the burning and calcined temperature was responsible for the formation of CaO with gaseous evolution of $\mathrm{CO}_{2}$, the reaction is not complete without the process route. Truly, the fermentation process increased the content of CaO obtained in the catalysts, but SFCTCPH has high conversion with $87.65 \%$ with a high FAEE yield of 98.94 (\% wt.).

The yield of FAEE was also high for CTCPH with 94.82 (\% wt.), but the value produced by BTCPH was the least with 90.20 (\% wt.) due to low CaO conversion of $68.20 \%$. This showed that the calcined fermented catalyst produced higher CaO-based content than the burnt and non-fermented catalysts (Adepoju, 2020)[18].

Table 5: BET and XRD analysis of the catalysts 


\begin{tabular}{|c|c|c|c|c|c|c|c|c|c|c|}
\hline \multirow[t]{2}{*}{ lysts } & \multirow[t]{2}{*}{$\beta\left(\mathrm{m}^{2} / \mathrm{g}\right)$} & \multirow{2}{*}{$\begin{array}{l}\mathrm{\lambda} \\
\left(\mathrm{cm}^{3} / \mathrm{g}\right)\end{array}$} & \multirow[t]{2}{*}{$\mathrm{CaO}(\%)$} & \multicolumn{3}{|c|}{ BS $\left(\mu\right.$ mole. $\left.g^{-1}\right)$} & \multirow[t]{2}{*}{ TBS } & \multirow[t]{2}{*}{ BSD $\left(\mu \mathrm{mole} / \mathrm{m}^{2}\right)$} & \multirow{2}{*}{$\begin{array}{l}\text { FAEE } \\
\text { (\%wt.) }\end{array}$} & \multirow[t]{2}{*}{ CA (wt.\%) } \\
\hline & & & & $400<1$ & $=650$ & $>650$ & & & & \\
\hline$\overline{{ }^{\mathrm{H}}}$ & 1.00 & 0.0015 & 68.20 & 36 & 140 & & 176 & 176.00 & 91.00 & 2.50 \\
\hline 'H & 1.10 & 0.0024 & 81.46 & 26 & 162 & & 188 & 170.91 & 94.00 & 2.50 \\
\hline СPH & 1.10 & 0.0030 & 87.65 & 22 & 174 & & 196 & 178.18 & 98.20 & 2.50 \\
\hline
\end{tabular}

$\boldsymbol{\beta}=$ Surface area, $\boldsymbol{\lambda}=$ Pore volume, $\mathrm{BS}=$ Basic site, $\mathrm{TBS}=$ Total basic site, $\mathrm{BSD}=\mathrm{Basic}$ site density, $\mathrm{GD}=\mathrm{Green}$ diesel, CA $=$ Catalyst amount

\subsection{Experimental results and the optimization of transesterification process variables}

\subsubsection{Experimental results}

Displayed in Table 3a are the 16 results obtained for every experimental run carried out and the predicted value by the HD using the three catalysts developed from cocoa pod husk (BTCPH, CTCPH, and CSFCTCPH). From the table, the FAEE highest yield obtained when BTCPH was used was 93. 50 (\%wt.) while the predicted value was 93.50 (\%wt.) at run 15, the highest value of FAEE yield obtained by CTCPH in FAEE2 was 94.50 (\%wt.) at run 15 with the same predicted value of 94.50 (\%wt.). However, the highest FAEE value obtained when CSFCTCPH was used as catalyst was 99.80 (\%wt.), but the predicted value was 99.84 (\%wt.) at run 10. These values indicated that the three developed catalysts are suitable for FAEE synthesis and can serve as feedstock for based catalyst in industrial application, but the calcined submerge fermented cocoa pod husk powder produced highest FAEE3 yield CSFCTCPH when compared with the yield associated with the use of BTCPH (93.50 (\%wt.)) and CTCPH (93.50 (\%wt.). Meanwhile, based on experimental and the predicted yield of FAEEs, the plots in Fig. 3(a) showed the relationship between the experimental results and the predicted values by the design software, the identifier of an appropriate exponent (Lambda $=1)$ to transform data into a normal shape due to residual error was as indicated in Fig. 3(b).

Usually, the Lambda values between -5 and +5 showed the transformation data has the highest likelihood of normal data. The value of lambda of 0.47 indicated the data obtained in this study were normal and have the function of $Y^{1}$ confirming the polynomial model choice accuracy.

Table 3a: Experimental results and the predicted value

\begin{tabular}{|c|c|c|c|c|c|c|c|c|c|c|}
\hline $\mathrm{SN}$ & $\mathrm{X}_{1}$ & $\mathrm{X}_{2}$ & $\mathbf{X}_{3}$ & $\mathrm{X}_{4}$ & FAEE1 & FAEE2 & FAEE3 & PFAEE1 & PFAEE2 & PFAEE3 \\
\hline 1 & 0.000 & 0.000 & 0.000 & 1.732 & 89.10 & 90.30 & 92.30 & 89.10 & 90.30 & 92.30 \\
\hline 2 & 0.000 & 0.000 & 0.000 & -0.269 & 90.20 & 91.40 & 93.80 & 90.20 & 91.40 & 93.80 \\
\hline 3 & -1.000 & -1.000 & -1.000 & 0.604 & 88.30 & 89.50 & 90.50 & 88.31 & 89.53 & 90.46 \\
\hline 4 & 1.000 & -1.000 & -1.000 & 0.604 & 90.10 & 91.00 & 93.00 & 90.09 & 90.98 & 93.04 \\
\hline 5 & -1.000 & 1.000 & -1.000 & 0.604 & 87.90 & 89.60 & 91.60 & 87.89 & 89.58 & 91.64 \\
\hline 6 & 1.000 & 1.000 & -1.000 & 0.604 & 88.60 & 89.80 & 91.70 & 88.61 & 89.83 & 91.66 \\
\hline 7 & -1.000 & -1.000 & 1.000 & 0.604 & 88.60 & 89.90 & 90.90 & 88.59 & 89.88 & 90.94 \\
\hline 8 & 1.000 & -1.000 & 1.000 & 0.604 & 90.60 & 92.00 & 96.24 & 90.61 & 92.02 & 96.20 \\
\hline 9 & -1.000 & 1.000 & 1.000 & 0.604 & 91.60 & 93.90 & 97.20 & 91.61 & 93.92 & 97.16 \\
\hline 10 & 1.000 & 1.000 & 1.000 & 0.604 & 92.60 & 94.90 & 99.80 & 92.59 & 94.87 & 99.84 \\
\hline 11 & 1.518 & 0.000 & 0.000 & -1.050 & 91.80 & 93.00 & 99.40 & 91.80 & 93.00 & 99.40 \\
\hline 12 & -1.518 & 0.000 & 0.000 & -1.050 & 84.50 & 90.00 & 93.00 & 84.50 & 90.00 & 93.00 \\
\hline 13 & 0.000 & 1.518 & 0.000 & -1.050 & 90.30 & 92.00 & 96.00 & 90.30 & 92.00 & 96.00 \\
\hline 14 & 0.000 & -1.518 & 0.000 & -1.050 & 82.50 & 84.40 & 86.80 & 82.50 & 84.40 & 86.80 \\
\hline 15 & 0.000 & 0.000 & 1.518 & -1.050 & 93.50 & 95.40 & 97.90 & 93.50 & 95.40 & 97.90 \\
\hline 16 & 0.000 & 0.000 & -1.518 & -1.050 & 80.30 & 83.20 & 85.00 & 80.30 & 83.20 & 85.00 \\
\hline
\end{tabular}

\subsubsection{Statistical optimization via ANOVA}

Displayed in Table 3b are the results of statistical optimization via ANOVA for the response surface quadratic model and the Fits statistics obtained through the catalytic performance during the transesterification reaction. Observation from the table showed that the Model F-values of 194.16 , 159.85, and 263.03 with 14 degree of freedom (df), implied the model were significant with P-values $<0.05$, but the model 194.16 with an F-value of $11,095.04$ is the most significant model (P-value $=0.0075$ ) compared with model 159.85 with F-value of 2283.63, and model 263.03 with model F- 
value of 1300.18. The table also displayed the significance of the quadratic model factors, values of "Prob $>F "<0.05$ shows variable terms are significant.

In this case, all the model terms were significant except $X_{1}^{2}$ and $X_{1} X_{3}$ when FAEE1 was considered, the non-significant quadratic terms found in FAEE2 production were $\mathrm{X}_{3}^{2}, \mathrm{X}_{1} \mathrm{X}_{2}, \mathrm{X}_{1} \mathrm{X}_{3}$, and $\mathrm{X}_{1} \mathrm{X}_{4}$, while only $\mathrm{X}_{4}, \mathrm{X}_{4}{ }^{2}$, and $\mathrm{X}_{1} \mathrm{X}_{4}$ were found non-significant when the analysis of the significant factors was carried out on FAEE3 production. Based on the results of Fit statistics datasets, the coefficient of determination obtained showed the model's predictions interaction was good $(>98 \%)$ with low standard deviations $(<0.20)$. The values also showed that there is a certainty above $98 \%$ that the model generated explained the data variability (Arjun et al., 2019)[26]. Meanwhile, the mean values obtained depicted the high accuracy of the data obtained for the variable factors.

Based on the optimization, the statistical model predicted a FAEE1 yield of 93.4998 (\%wt.), FAEE2 yield of 95.2411 (\%wt.), and FAEE3 yield of 99.8081 (\%wt.) at the process variables conditions of $78.58 \mathrm{~min}, 3.37$ (wt.\%), $79.23{ }^{\circ} \mathrm{C}$, and 1:6.66 (vol/vol), respectively (Supplementary file). The values were validated by performing three experiments under the same condition, the average values of fatty acid ethyl ester obtained were 92.8100 (\%wt.) for FAEE1, 93.0200 (\%wt.) for FAEE2, and 99.6400 (\%wt.) for FAEE3, respectively. These values indicated that all catalysts developed were good as feedstock for industrial applications, but fermented catalyst developed catalyst produced the highest biodiesel yield among others.

Table 3b: Anova and test of significant table 


\begin{tabular}{|c|c|c|c|c|c|c|c|c|c|c|c|c|c|}
\hline \multirow[t]{2}{*}{ iurce } & \multicolumn{3}{|c|}{ Sum of Squares } & \multirow[t]{2}{*}{$\mathrm{df}$} & \multicolumn{3}{|c|}{ Mean Square } & \multicolumn{3}{|c|}{ F-Value } & \multicolumn{3}{|c|}{ Prob > F } \\
\hline & 1 & 2 & 3 & & 1 & 2 & 3 & 1 & 3 & & 1 & 2 & 3 \\
\hline \multirow[t]{15}{*}{$\overline{\text { Jdel }}$} & 194.16 & 159.85 & 263.03 & 14 & 13.87 & 11.42 & 18.79 & 11095.04 & 2283.63 & 1300.18 & 0.0074 & 0.0164 & 0.0217 \\
\hline & 21.80 & 6.94 & 32.54 & 1 & 21.80 & 6.94 & 32.54 & 17442.09 & 1387.81 & 2251.71 & 0.0048 & 0.0171 & 0.0134 \\
\hline & 17.70 & 23.83 & 44.26 & 1 & 17.70 & 23.83 & 44.26 & 14159.69 & 4766.88 & 3063.24 & 0.0053 & 0.0092 & 0.0115 \\
\hline & 64.58 & 68.17 & 108.11 & 1 & 64.58 & 68.17 & 108.11 & 51663.48 & 13633.9 & 7481.75 & 0.0028 & 0.0055 & 0.0074 \\
\hline & 18.59 & 5.93 & 0.56 & 1 & 18.59 & 5.93 & 0.56 & 14874.14 & 1186.82 & 38.91 & 0.0052 & 0.0185 & 0.1012 \\
\hline & 0.023 & 2.61 & 12.09 & 1 & 0.023 & 2.61 & 12.09 & 18.03 & 521.63 & 836.54 & 0.1473 & 0.0279 & 0.0220 \\
\hline & 2.98 & 3.70 & 2.80 & 1 & 2.98 & 3.70 & 2.80 & 2386.14 & 740.98 & 193.46 & 0.0130 & 0.0234 & 0.0457 \\
\hline & 1.42 & 0.55 & 2.62 & 1 & 1.42 & 0.55 & 2.62 & 1134.24 & 110.97 & 181.25 & 0.0189 & 0.0603 & 0.0472 \\
\hline & 7.41 & 3.63 & 2.20 & 1 & 7.41 & 3.63 & 2.20 & 5925.43 & 726.94 & 152.05 & 0.0083 & 0.0236 & 0.0515 \\
\hline & 0.55 & 0.72 & 3.30 & 1 & 0.55 & 0.72 & 3.30 & 441.00 & 144.00 & 228.54 & 0.0303 & 0.0529 & 0.0420 \\
\hline & 0.031 & 0.25 & 3.56 & 1 & 0.031 & 0.25 & 3.56 & 25.00 & 49.00 & 246.67 & 0.1257 & 0.0903 & 0.0405 \\
\hline & 8.62 & 0.44 & 1.83 & 1 & 8.62 & 0.44 & 1.83 & 6898.37 & 88.17 & 126.57 & 0.0077 & 0.0675 & 0.0564 \\
\hline & 5.95 & 8.00 & 12.65 & 1 & 5.95 & 8.00 & 12.65 & 4761.00 & 1600.00 & 875.46 & 0.0092 & 0.0159 & 0.0215 \\
\hline & 13.92 & 9.25 & 9.72 & 1 & 13.92 & 9.25 & 9.72 & 11136.70 & 1849.97 & 672.64 & 0.0060 & 0.0148 & 0.0245 \\
\hline & 31.57 & 20.83 & 12.68 & 1 & 31.57 & 20.83 & 12.68 & 25255.75 & 4165.73 & 877.26 & 0.0040 & 0.0099 & 0.0215 \\
\hline :sidual & 0.00125 & 0.005 & 0.014 & 1 & 0.00125 & 0.005 & 0.014 & - & - & - & - & - & - \\
\hline $\begin{array}{l}\text { Ir } \\
\text { tal }\end{array}$ & 194.16 & 159.86 & 263.04 & 15 & - & - & - & - & - & - & - & - & - \\
\hline & \multicolumn{8}{|c|}{ Significance Factors @ $\mathrm{p}<0.0500$} & \multicolumn{5}{|c|}{ Non-Significant Factors $p>0.0500$} \\
\hline$\overline{\text { EE1 }}$ & \multicolumn{8}{|c|}{$\mathrm{X}_{1}, \mathrm{X}_{2}, \mathrm{X}_{3}, \mathrm{X}_{4}, \mathrm{X}_{2}^{2}, \mathrm{X}_{3}^{2}, \mathrm{X}_{4}^{2}, \mathrm{X}_{1} \mathrm{X}_{2}, \mathrm{X}_{1} \mathrm{X}_{4}, \mathrm{X}_{2} \mathrm{X}_{3}, \mathrm{X}_{2} \mathrm{X}_{4}$, and $\mathrm{X}_{3} \mathrm{X}_{4}$} & \multicolumn{5}{|c|}{$\mathrm{X}_{1}^{2}$ and $\mathrm{X}_{1} \mathrm{X}_{3}$} \\
\hline EE2 & \multicolumn{8}{|c|}{$\mathrm{X}_{1}, \mathrm{X}_{2}, \mathrm{X}_{3}, \mathrm{X}_{4}, \mathrm{X}_{2}^{2}, \mathrm{X}_{1}^{2}, \mathrm{X}_{4}^{2}, \mathrm{X}_{2} \mathrm{X}_{3}, \mathrm{X}_{2} \mathrm{X}_{4}$, and $\mathrm{X}_{3} \mathrm{X}_{4}$} & \multicolumn{5}{|c|}{$\mathrm{X}_{3}^{2}, \mathrm{X}_{1} \mathrm{X}_{2}, \mathrm{X}_{1} \mathrm{X}_{3}$, and $\mathrm{X}_{1} \mathrm{X}_{4}$} \\
\hline EE3 & \multicolumn{8}{|c|}{$\mathrm{X}_{1}, \mathrm{X}_{2}, \mathrm{X}_{3}, \mathrm{X}_{1}^{2}, \mathrm{X}_{2}^{2}, \mathrm{X}_{3}^{2}, \mathrm{X}_{1} \mathrm{X}_{2}, \mathrm{X}_{1} \mathrm{X}_{3}, \mathrm{X}_{2} \mathrm{X}_{3}, \mathrm{X}_{2} \mathrm{X}_{4}$, and $\mathrm{X}_{3} \mathrm{X}_{4}$} & \multicolumn{5}{|c|}{$\mathrm{X}_{4}, \mathrm{X}_{4}^{2}$, and $\mathrm{X}_{1} \mathrm{X}_{4}$} \\
\hline \multicolumn{14}{|c|}{ Fits statistics } \\
\hline & \multicolumn{2}{|c|}{ R-Squared } & \multicolumn{2}{|c|}{ Adj R-Square } & \multicolumn{2}{|c|}{ Pred R-Squared } & \multicolumn{2}{|c|}{ Adeq Precision } & $\begin{array}{l}\text { Std. } \\
\text { Dev. }\end{array}$ & \multicolumn{3}{|l|}{ Mean } & \\
\hline EE1 & \multicolumn{2}{|c|}{$99.99 \%$} & \multicolumn{2}{|c|}{$99.98 \%$} & \multicolumn{2}{|c|}{$99.99 \%$} & \multicolumn{2}{|c|}{385.597} & 0.035 & \multicolumn{3}{|l|}{88.78} & \\
\hline EE2 & \multicolumn{2}{|c|}{$99.99 \%$} & \multicolumn{2}{|c|}{$99.96 \%$} & $99.98 \%$ & & 178. & & 0.071 & 90.64 & & & \\
\hline EE3 & $99.98 \%$ & & 99.9 & & $99.97 \%$ & & 127.5 & & 0.12 & 93.45 & & & \\
\hline
\end{tabular}

Meanwhile, the second-order mathematical differential equation that correlated the response variables (FAEE1, FAEE2, and FAEE3) with the constraint variables $\left(\mathrm{X}_{1}\right.$ : reaction time, $\mathrm{X}_{2}$ : catalyst amount, $\mathrm{X}_{3}$ : reaction temperature, and $\mathrm{X}_{4}$ : EtOH/OMR) are presented in Eqn. (2), (3), and (4), respectively.

Final equation in terms of coded: (see Equations 2-4 in the Supplementary Files)

\subsection{Catalytic refining and reusability test}

Before catalyst reusability, after recycled at the completion of reaction, the catalyst obtained was refined following the step by step procedure of Adepoju et al. (2020b)[24] with slight alterations. The recycled catalyst was washed with alcohol to eliminate the dirt at the interface of catalyst that occurred during the transesterification, centrifuged at $4500 \mathrm{rpm}$ in an in-built system vacuum centrifuge. The washed catalyst was obtained by filtration, and then oven-dried at $120^{\circ} \mathrm{C}$ for $45 \mathrm{~min}$, cooled to room temperature before reused. The reusability test was carried out on the derived catalysts in many cycles, at the following reaction conditions: the reaction time of $70 \mathrm{~min}$, the catalyst amount of 2.50 (\%wt.), the reaction temperature of $70^{\circ} \mathrm{C}$, and 1:4 (vol/vol) EtOH/OMR. 
The results obtained were illustrated using Microsoft Excel 2010 to plots the data. The plots showed the activities of the catalysts maintained stability from the first cycle to the $4^{\text {th }}$ cycle with a negligible decrease in catalysts strength, however, a significant dropped was noticed in the $5^{\text {th }}$ and $6^{\text {th }}$ cycles, hence, catalysts refining and reusability were stopped at the $4^{\text {th }}$ cycle. This observation was in line with what was earlier reported that catalyst basic strength decreases due to continuous intermediate products monoglyceride and diglyceride resulted as a result of the reaction, which obstructed the catalyst holes. The formation of water to oxygen reaction that occurred at the catalyst surface also reduces the catalyst sensitivity (Trisupakitti et al., 2017; Adepoju et al., 2020a; Adepoju et al., 2020c)[16, 24, 25].

\subsection{Fatty acid ethyl ester (FAEEs) qualities and its comparison with standard}

Table 6 displayed the results of the qualities of the blended oil $\left(\mathrm{BTO}_{60}\right)$ and the FAEEs produced with the references to ASTM and EN. Observation from the table indicated that there were significant changes as the oil was converted to biodiesel due to transesterification with developed catalysts, the effect of alcohol, reaction time, and reaction temperature. However, there were no distinct differences in the values of the properties of the three biodiesel (FAEE1, FAEE2, and FAEE3), except a slight difference noticed in the iodine and acid value of the FAEE1 produced by the BTCPH, this may be attributed to the powder preparation processes. Burning could result in the loss of the volatile nutrient, making the ash more acidic and increase the unsaturation level of the biodiesel when used during the transesterification process (Betiku et al., 2017)[11]. The physicochemical properties of the FAEE2 and FAEE3 remain almost the same; this could be attributed to the calcination process involved in the sample preparation, causing the gaseous evolution of $\mathrm{CO}_{2}$ from the $\mathrm{CaCO}_{3}$ at a controlled temperature more than burning. The properties of biodiesel produced were in the range of recommended standard stated by ASTM D6751 [22] and EN 14214[23].

Table 6: Qualities of the produced FAEEs

\begin{tabular}{|c|c|c|c|c|c|c|}
\hline \multirow[t]{2}{*}{ Parameter } & \multirow[t]{2}{*}{$\mathrm{BTO}_{60}$} & \multicolumn{3}{|c|}{ FAEEs (\%wt.) } & \multirow[t]{2}{*}{ ASTM D6751 [22] } & \multirow[t]{2}{*}{ EN 14214 [23] } \\
\hline & & FAEE1 & FAEE2 & FAEE3 & & \\
\hline Colour@ $27^{\circ} \mathrm{C}$ & Brownish-yellow & Light yellowish & Light yellowish & Light yellowish & - & - \\
\hline State @ room temp & Liquid & Liquid & Liquid & Liquid & Liquid & Liquid \\
\hline Specific gravity & 0.902 & 0.864 & 0.864 & 0.864 & - & $860-900$ \\
\hline Viscosity@ $40^{\circ} \mathrm{C} /\left(\mathrm{mm}^{2} / \mathrm{s}\right)$ & 22.30 & 2.78 & 2.78 & 2.78 & $1.9-6.0$ & $3.5-5.0$ \\
\hline Moisture content (\%) & 0.02 & $<0.01$ & $<0.01$ & $<0.01$ & $<0.03$ & 0.02 \\
\hline \%FFA (as oleic acid) & 0.1745 & 0.032 & 0.021 & 0.018 & $0.40 \max$ & $0.25 \max$ \\
\hline Acid value (mg KOH/g oil) & 0.249 & 0.064 & 0.042 & 0.036 & $0.80 \max$ & $0.50 \max$ \\
\hline Iodine value ( $\mathrm{g} \mathrm{I}_{2} / 100 \mathrm{~g}$ oil) & 58.88 & 56.62 & 53.62 & 53.62 & ND & $120 \max$ \\
\hline Saponification value (mg $\mathrm{KOH} / \mathrm{g}$ oil) & 180.00 & 178.43 & 176.32 & 172.22 & $236.66-253.04$ & ND \\
\hline Peroxide value (meq $\mathrm{O}_{2} / \mathrm{kg}$ oil) & 12.65 & 8.90 & 8.70 & 8.60 & ND & 12.85 \\
\hline HHV (MJ/kg) & 41.17 & 41.26 & 41.40 & 41.52 & ND & ND \\
\hline Cetane number & 63.39 & 64.15 & 65.19 & 65.92 & $57 \min$ & $51 \mathrm{~min}$ \\
\hline API gravity & 22.30 & 32.27 & 32.27 & 32.27 & $30-42$ & ND \\
\hline Diesel index & 49.50 & 50.26 & 51.30 & 52.04 & $50.4 \mathrm{~min}$ & ND \\
\hline
\end{tabular}

$\mathrm{ND}=$ Not Determine

\subsection{Comparative studies of this work with earlier reported works}

Table 7 showed the use of single heterogeneous based catalyst derived from different agricultural wastes for biodiesel production using single/blended oil in a different ratio (Subramaniapillai et al., 2019; Fayazishishvan et al., 2018; Tadesse et al., 2019)[8, 27, 28]. Falowo et al. (2020) [17] derived a based catalyst from the mixture of three agricultural wastes, while Adepoju et al. in their various reported studies, derived novel based catalysts from the mixture of different biomass wastes for biodiesel synthesis. Except the work of Victoria et al (2017) [29], where the authors established the optimum biodiesel yields from banana fruit peel and cocoa pod husk, no single report has ever derived three CaO-based catalysts from single biomass waste and compares their efficiencies in fatty acid ethyl ester (FAEE) synthesis. Hence, with respect on earlier reports, there exists no basis, but this study showed that the derived catalysts produced a high yield of biodiesel, and the catalysts can be used in industrial as feedstock.

Table 7: Comparing this study with reported literature studies 


\begin{tabular}{|c|c|c|c|c|c|c|c|}
\hline $\begin{array}{l}\text { Blended } \\
\text { Oil }\end{array}$ & $\begin{array}{l}\text { Blending } \\
\text { ratio } \\
\text { (vol/vol) }\end{array}$ & Catalysts & $\begin{array}{l}\text { Calcination } \\
\text { temperature and } \\
\text { duration }\end{array}$ & $\begin{array}{l}\text { \% } \\
\mathrm{CaO} / \mathrm{KOH} \\
\text { conversion }\end{array}$ & $\begin{array}{l}\text { Catalyst } \\
\text { analysis }\end{array}$ & $\begin{array}{l}\% \\
\text { Biodiesel } \\
\text { yield }\end{array}$ & References \\
\hline $\begin{array}{l}\text { Cucurbita pepo }+ \\
\text { Chrysophyllum albidum }+ \\
\text { papaya oil }\end{array}$ & 33:33:34 & $\begin{array}{l}\text { Mixture of Citrullus lanatus - } \\
\text { Musa acuminate } \\
\text { peels }\end{array}$ & $\begin{array}{l}700{ }^{\circ} \mathrm{C} \text { for } \\
4 \mathrm{~h}\end{array}$ & $\begin{array}{l}\mathrm{CaO}= \\
78.74 \%\end{array}$ & $\begin{array}{l}\text { XRD, SEM, } \\
\text { BET and } \\
\text { FTIR }\end{array}$ & 93.45 & $\begin{array}{l}\text { Adepoju et } \\
\text { al. (2020a)[21] }\end{array}$ \\
\hline $\begin{array}{l}\text { Irvingia gabonensis } \\
+ \text { Pentaclethra macrophylla }+ \\
\text { Elais guineensis oil }\end{array}$ & 33:33:34 & $\begin{array}{l}\text { Mixture of Wood ash-Snail } \\
\text { shell- eggshell }\end{array}$ & $\begin{array}{l}900{ }^{\circ} \mathrm{C} \text { for } \\
3 \mathrm{~h}\end{array}$ & $\begin{array}{l}\mathrm{CaO}= \\
98.50 \%\end{array}$ & $\begin{array}{l}\text { SEM, EDX- } \\
\text { ray, FTIR } \\
\text { and BET }\end{array}$ & 97.22 & $\begin{array}{l}\text { Adepoju et } \\
\text { al. (2020b) [24] }\end{array}$ \\
\hline $\begin{array}{l}\text { Calophyllum inophyllum-waste } \\
\text { cooking oil }\end{array}$ & $50: 50$ & Donax deltoids shells & $\begin{array}{l}105^{\circ} \mathrm{C} \text { for } \\
24 \mathrm{~h}\end{array}$ & $\begin{array}{l}\mathrm{CaO}= \\
70.87 \%\end{array}$ & $\begin{array}{l}\text { XRD, SEM, } \\
\text { BET, and } \\
\text { FTIR }\end{array}$ & 96.50 & $\begin{array}{l}\text { Subramaniapillai et } \\
\text { al. (2019) [8] }\end{array}$ \\
\hline Waste cooking oil (WCO) & - & $\mathrm{Ca}\left(\mathrm{NO}_{3}\right) \cdot 4 \mathrm{H}_{2} \mathrm{O}$ & $\begin{array}{l}500^{\circ} \mathrm{C} \text { for } \\
5 \mathrm{~h}\end{array}$ & $\mathrm{CaO}$ & $\begin{array}{l}\text { XRD and } \\
\text { SEM }\end{array}$ & 96.00 & $\begin{array}{l}\text { Tadesse et al. } \\
\text { (2019) [28] }\end{array}$ \\
\hline Sunflower oil & - & Chicken eggshells & $\begin{array}{l}900{ }^{\circ} \mathrm{C} \text { for } \\
3 \mathrm{~h}\end{array}$ & $\mathrm{CaO}$ & $\begin{array}{l}\text { SEM, TGA, } \\
\text { XRD }\end{array}$ & $83.20 \%$ & $\begin{array}{l}\text { Fayazishishvan et } \\
\text { al. (2018)[27] }\end{array}$ \\
\hline Palm Kernel oil & - & $\begin{array}{l}\text { Banana fruit peel } \\
\text { Cocoa pod husk }\end{array}$ & $\begin{array}{l}650^{\circ} \mathrm{C} \text { for } \\
4 \mathrm{~h}\end{array}$ & $\mathrm{CaO}$ & & $99.30 \% \mathrm{~S}$ & $\begin{array}{l}\text { Victoria et al. } \\
(2017)[29]\end{array}$ \\
\hline $\begin{array}{l}\text { Carica papaya +Citrus } \\
\text { sinesis }+ \text { Hibiscus sabdariffa }+ \\
\text { Waste used oil }\end{array}$ & $25: 25: 25: 25$ & $\begin{array}{l}\text { Mixture of Lattorina littorea- } \\
\text { Mactra coralline Shell }\end{array}$ & $\begin{array}{l}900^{\circ} \mathrm{C} \text { for } \\
3 \mathrm{~h}\end{array}$ & $\begin{array}{l}\mathrm{CaO} \\
=99.02\end{array}$ & $\begin{array}{l}\text { SEM, EDX, } \\
\text { FTIR }\end{array}$ & $99.78 \%$ & $\begin{array}{l}\text { Adepoju et al. } \\
(2020 c)[25]\end{array}$ \\
\hline $\begin{array}{l}\text { Luffa cylindrical+ } \begin{array}{r}\text { Datura } \\
\text { stramonium+ } \\
\text { siceraria oil }\end{array}\end{array}$ & $29: 50: 21$ & $\begin{array}{l}\text { Mixture of Cucurbita } \\
\text { pepo- Musa acuminate - } \\
\text { Citrullus lanatus peels }\end{array}$ & $\begin{array}{l}650{ }^{\circ} \mathrm{C} \text { for } \\
3 \mathrm{~h}\end{array}$ & $\begin{array}{l}\mathrm{CaO}= \\
75.65 \%\end{array}$ & $\begin{array}{l}\text { SEM, EDX- } \\
\text { ray, FTIR, } \\
\text { and BET }\end{array}$ & $96.50 \%$ & $\begin{array}{ll}\text { Adepoju } & \text { et } \\
\text { al (2020d)[30] } & \end{array}$ \\
\hline \multirow[t]{3}{*}{$\begin{array}{l}\text { Beef Tallow blend }+ \text { Waste } \\
\text { used vegetable oil }\end{array}$} & $60: 40$ & $\begin{array}{l}\text { Theobroma cacao pod husks } \\
\text { Burnt }\end{array}$ & $\begin{array}{l}\text { Uncontrolled } \\
\text { temperature }\end{array}$ & $\begin{array}{l}\mathrm{CaO} \\
68.20 \%\end{array}$ & \multirow[t]{3}{*}{$\begin{array}{l}\text { XRD, SEM, } \\
\text { BET, and } \\
\text { FTIR }\end{array}$} & $92.81 \%$ & THIS STUDY \\
\hline & & Calcined & $\begin{array}{l}750{ }^{\circ} \mathrm{C} \text { for } \\
4 \mathrm{~h}\end{array}$ & $81.46 \%$ & & $93.02 \%$ & \\
\hline & & $\begin{array}{l}\text { Submerged } \\
\text { calcined }\end{array}$ & $\begin{array}{l}750{ }^{\circ} \mathrm{C} \text { for } \\
4 \mathrm{~h}\end{array}$ & $87.65 \%$ & & $99.64 \%$ & \\
\hline
\end{tabular}

\section{Conclusion}

The blending ratio of oil 60:40 $\left(\mathrm{BTO}_{60}\right)$ effectively produced a low oil acid value. Three novel catalysts derived using Theobroma cacao pod husks were demonstrated as the potential catalysts for FAEEs production and their efficacy might be ascribed to the high proportion of calcium existing. A hybrid design established an optimum value of 92.81 (\%wt.) for FAEE1, 93.02 (\%wt.) for FAEE2, and 99.64 (\%wt.) for FAEE3, for transesterification process as the reaction time of $78.58 \mathrm{~min}$, catalyst amount of 3.37 (wt.\%), reaction temperature of $79.23{ }^{\circ} \mathrm{C}$, and $\mathrm{EtOH} / \mathrm{OMR}$ of $1: 6.66$ (vol/vol), respectively. Based on catalyst BET adsorption analysis, the percentage CaO-based obtained from the developed catalysts showed Theobroma cacao pod husks could be used as industrial feedstock, and the quality of the FAEEs proved are within the ASTM D-6751 and EN 14214 biodiesel recommended standards. 


\section{Declarations}

\subsection{Availability of data and materials}

All data produced or examined throughout this work are encompassed in this published article.

\subsection{Competing interests}

The authors affirm that they have no opposing interests.

\subsection{Funding}

This work receives no fund from University, Private organization, or Government body.

\subsection{Authors' contributions}

Adepoju T. F: Conceptualization, Methodology, Software, Validation, Formal Analysis, Investigation, Resources, Data Curation, Writing-Original Draft, Supervision.

Ibeh, M. A: Formal Analysis, Investigation, Resources, Data Curation, Provide Financial Support, Methodology, Software

Babatunde, E.O: Methodology, Software, Validation, Formal Analysis, Methodology, Investigation, Resources, Provide Financial Support

Asuquo, A. J: Formal Analysis, Investigation, Resources, Data Curation, Methodology

Eloboka, C: Investigation, Resources, Data Curation, Methodology

\subsection{Acknowledgment}

Authors acknowledge the effort of Technologists of the Department of Chemical Engineering, Akwa Ibom State University, Nigeria. The effort of Eloboka, C of the School of Chemical and Minerals Engineering, Northwest University, Potchefstroom, South Africa, is also appreciated. Especial thanks to my project students and staff of Chemical Engineering, Akwa Ibom State University, Nigeria.

\section{References}

[1] Dizge N, Keskinler B, Tanriseven A. Biodiesel production from canola oil by using lipid immobilized onto hydrophobic microporous strenedivinylbenzene copolymer. Biochemic Engineer Journ. 2009; 44: 220-225.

[2] Milan DK, Ana VV, Natasa MJ, Olivera SS, Vlada BV. Optimization and kinetic of esterification of the oil obtained from plum stones as a pretreatment step in biodiesel production. Waste Managem. 2016;48:619-629.

[3] Vadery V, Narayanan BN, Ramakrishnan RM, Cherikkallinmel SK, Sugunan S, Narayanan DP. Room temperature production of jatropha biodiesel over coconut husk ash. Energ. 2014; 70: 588-594.

[4] Bazargan A, Kostic MD, Stamenkovic OS, Veljkovic VB, McKaV G. Palm kernel shell gasification residues as precursors for a calcium based catalyst for biodiesel production. Fuel. 2015; 150: 519-525.

[5] Chouhan APS and Sarma AK. Biodiesel production from Jatropha curcus L. oil using Lemna perpusila Torrey ash as heterogeneous catalyst. Biomas Bioenerg. 2013; 55:386-390.

[6] Rezaei R, Mohadesi M, Moradi GR. Optimization of biodiesel production using waste mussel shell catalyst. Fuel. 2013; 109:534-541.

[7] Ikbal BL, Kalyani R, Rajat G, Sushovan C, Bappi P, Laithazuala R. Waste snail shell derived heterogeneous catalyst for biodiesel production by the transesterification of soybean oil. RSC Adv. 2018; 8:20131. Doi: 10.1039/c8ra02397b

[8] Subramaniapillai N, Govindaraj V, Muthusamy B. Process optimization of Calophyllum inophyllum-waste cooking oil mixture for biodiesel production using Donax deltoids shells as Heterogeneous catalyst. Sustain Environ Res. 2019; 29: 2351-2362. https://doi.org/10.1186/s42834-0190015-6.

[9] Adepoju TF, Rasheed B, Olatunji MO, Ibeh MA, Ademiluyi FT, Olatunnbosun BE. Modeling and optimization of lucky nut seed by pearl spar catalysed transesterification. Heliyon, 2018; 4:e00798, doi: 10.1016j.

[10] Betiku E, Ajala SO. Modelling and Optimization of Thevetia peruviana (yellow oleander) oil biodiesel synthesis via Musa paradisiacal (plantain peels) as heterogeneous catalyst: a case of artificial neural network vs. response surface methodology. Ind Crops Prod. 2015;53:314-322. 
[11] Betiku E, Etim AO, Pereore 0, Ojumu TV. Two-step conversion of neem seed (Azadirachta indica) oil into fatty methyl esters using a bio-base catalyst: An example of cocoa pod husk. Energ \& Fuels 2017; 31:6182-6193 (America Chemical Society)

[12] Nath B, Das B, Kalita P, Basumatary S. Waste to value addition: Utilization of waste Brassica nigra plant derived novel green heterogeneous base catalyst for effective synthesis of biodiesel. J. of Clean Prod. 2019; 239:118112.

[13] Balajii M, Niju S. Banana peduncle-A green and renewable heterogeneous base catalyst for biodiesel production from Ceiba pentandra oil. Renew Energ., 2020; 146: 2255-2269.

[14] Minakshi G, Khairujjaman L, Atanu KP, Niran D, Mrutyunjay M, Imon KG, Anil H, Utpal B, Dhanapati D. Carica papaya stem: A source of versatile heterogeneous catalyst for biodiesel production and $\mathrm{CeC}$ bond formation. Renew. Energ. 2020; 147:541-555.

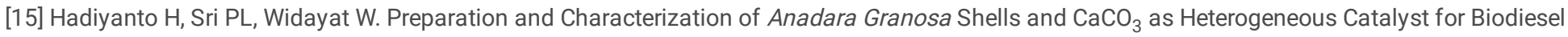
Production. BCREC. 2016; 11:21-26.

[16] Trisupakitti S, Ketwong C, Senajuk W, Phukapak C, Wiriyaumpaiwong C. Golden Apple Cherry Snail Shell as Catalyst for Heterogeneous Transesterification of Biodiesel. Brazilian J Chem Eng. 2019; 35:1283-1291

[17] Falowo OA, Omoniyi P, Ojumu TV, Betiku E. Sustainable biodiesel synthesis from Honne-Rubber-Neem oil blend with a novel mesoporous base catalyst synthesis from a mixture of three agrowastes, Cataly. 2020; 10:1-24.

[18] Adepoju TF. Optimization processes of biodiesel production from pig and Neem (Azadirachta indica A.Juss) seeds blend oil using alternative catalysts from waste biomass. Ind Crops Prod. 149 (2020) 112334.

[19] AOAC. Official methods of analyses of the Association of Official Analytical Chemists. 1990

[20] AOAC. Official methods of analyses of the Association of Official Analytical Chemists. 1997

[21] Adepoju TF, Ibeh MA, Babatunde EO, Asuquo AJ. Methanolysis of CaO based catalyst derived from egg shell-snail shell-wood ash mixed for fatty acid methylester (FAME) synthesis from a ternary mixture of Irvingia gabonensis -Pentaclethra macrophylla - Elais guineensis oil blend: An application of simplex lattice and central composite design optimization. Fuel. 2020a; 275: 117997.

[22] ASTM D6751. Standard Test Method for Gross Calorific Value of Oil, Water, Coal and Coke by the adiabatic Bomb Calorimeter from SAI Global.

[23] EN 14214. European Committee for Standardization, describing the requirements and test methods for FAME.

[24] Adepoju TF, Ibeh MA, Babatunde EO, Asuquo AJ. Biodiesel Production from Underutilized Oil-Seed via a Solid Based Catalyst Synthesized from the Mixture of three Agricultural Waste Peels. BAB_2020b_453 (Accepted)

[25] Adepoju TF, Ibeh MA, Babatunde EO, Asuquo AJ. Data on the derived mesoporous based catalyst for the synthesized of fatty acid methyl ester (FAME) from ternary oil blend: An optimization approach. Data in Brief 30 (2020) 105514

[26] Arjun CG, Jounnever MG, Meljane JA, Rohoney SV, Jay. Laranang R-L, Val Irvin FM, Renato OA, Alexander LI. Response surface optimization of biodiesel yield from pre-treated waste oil of rendered pork from a food processing industry. Bioresourc and Bioprocess. $2019 ; 6$ : 48.

https//:10.1186/s40643-019-02842.

[27] Fayazishishvan E, Ghobadian B, Van de Bovenkamp HK, Najafi G, Hosseinzadehsamani B, Heeras H J, Yuen J. Optimization of Biodiesel Production over Chicken Eggshell-Derived CaO Catalyst in a Continuous Centrifugal Contractor Separator. IECR. 2018;N57:12742-12755. https://doi.org/10.1021/acs.iecr.8b02678.

[28] Tadesse AD, Tadios TM, Yedilfan SM. Optimized Biodiesel Production from Waste Cooking Oil (WCO) using Calcium oxide (CaO) Nano-catalyst. Scientif Reports, 2019;9:18982. https://doi.org/10.1038/s41598-019-55403-4.

[29] Victoria OO, Ayo JA, Oluwaseyi OO, Omowumi OA, Niyi BI, Anietie OE, Eriola B. Application of Agricultural Waste-Based Catalysts to Transesterification of Esterified Palm Kernel Oil Biodiesel: A case of Banana Fruit Peel Versus Cocoa Pod Husk. Wast Biomas Valoriza, (2017) https://doi.org/10.1007/s12649-017-0152-2

[30] Adepoju TF, Ibeh MA, Udoetuk EN, Asuquo AJ, Babatunde EO. Quaternary blend of Carica papaya - Citrus sinesis - Hibiscus sabdariffa - Waste used oil for biodiesel synthesis using CaO-based catalyst derived from binary mix of Lattorina littorea and Mactra coralline Shell. RENE-D-2020d00352. (Accepted)

\section{Figures}




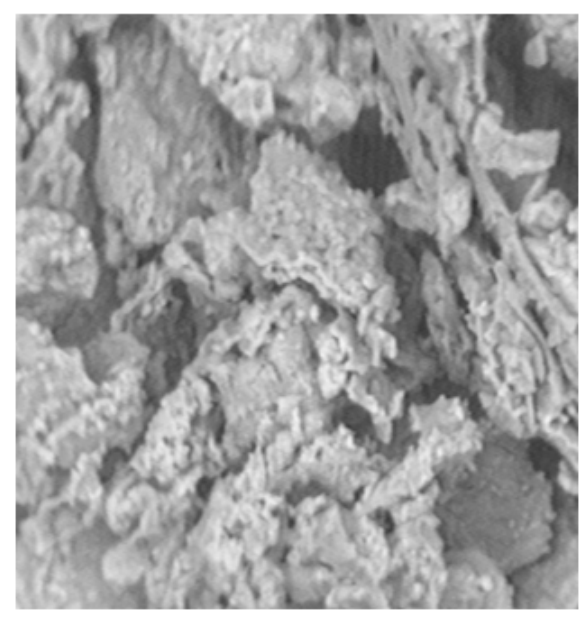

BTCPH

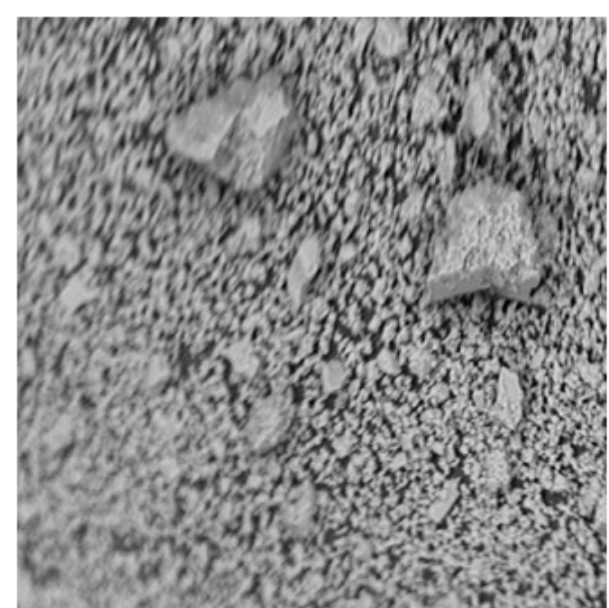

$\mathrm{CTCPH}$

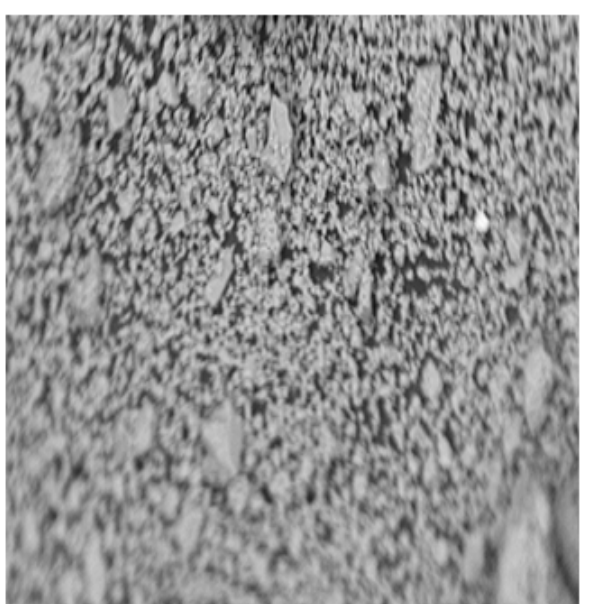

SFCTCPH

Figure 1

(a-c): SEM images of calcined catalysts

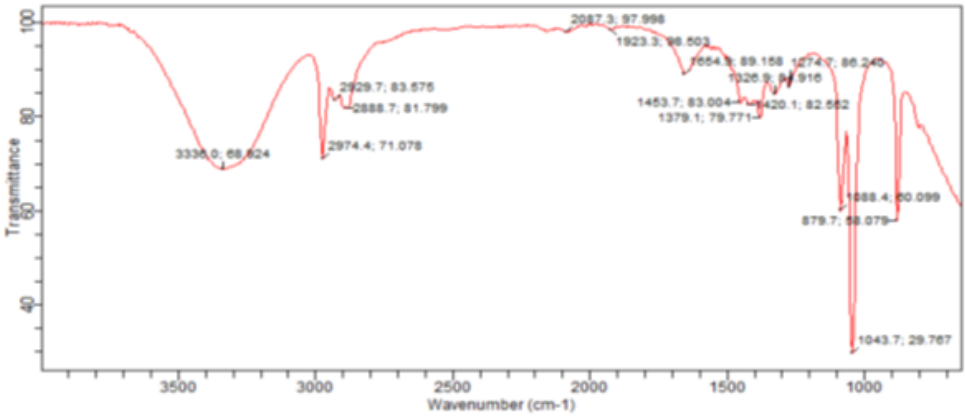

BTCHP
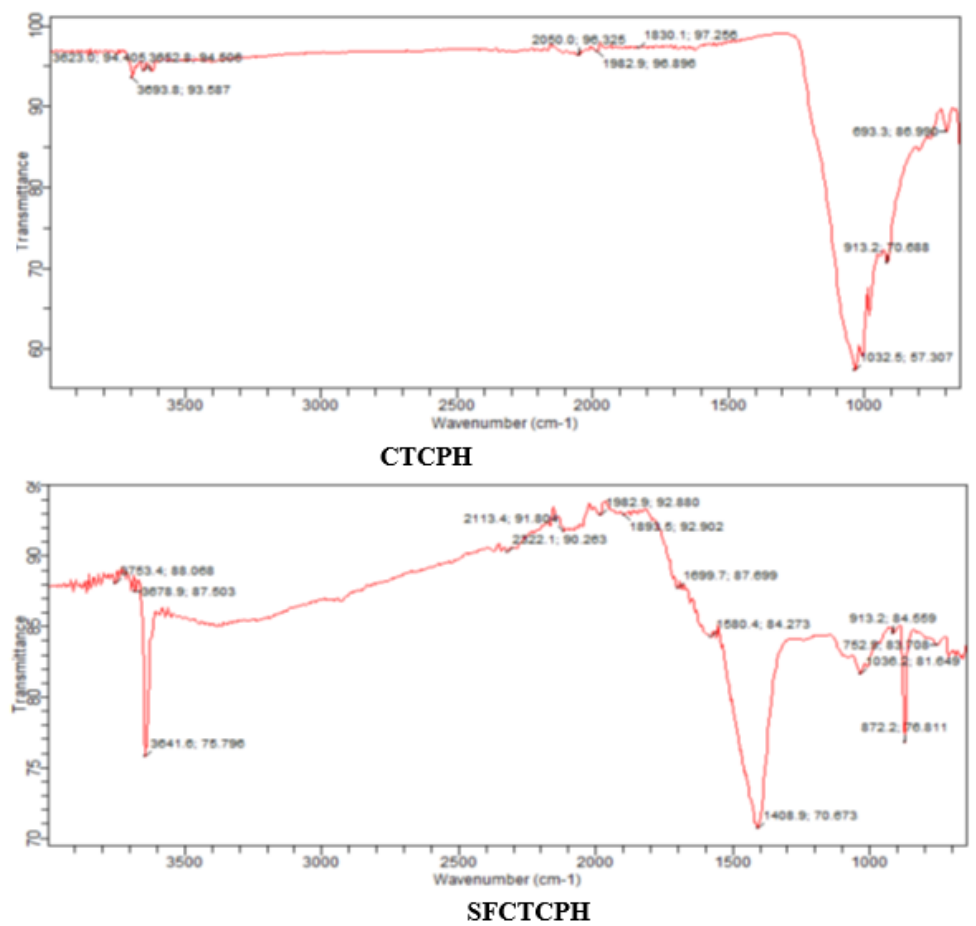

Figure 2 
FTIR spectral analysis of the catalysts and the mixed catalyst
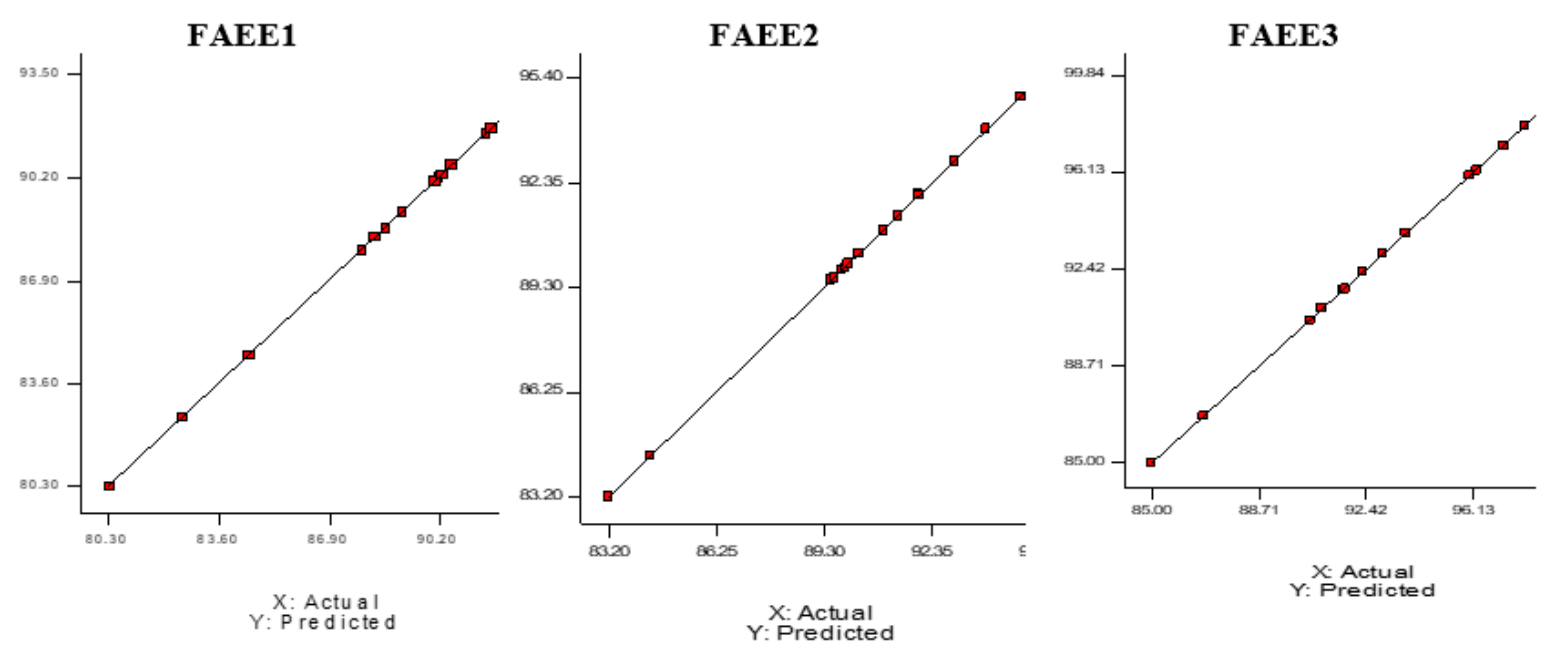

Fig. 2a: Predicted against Actual
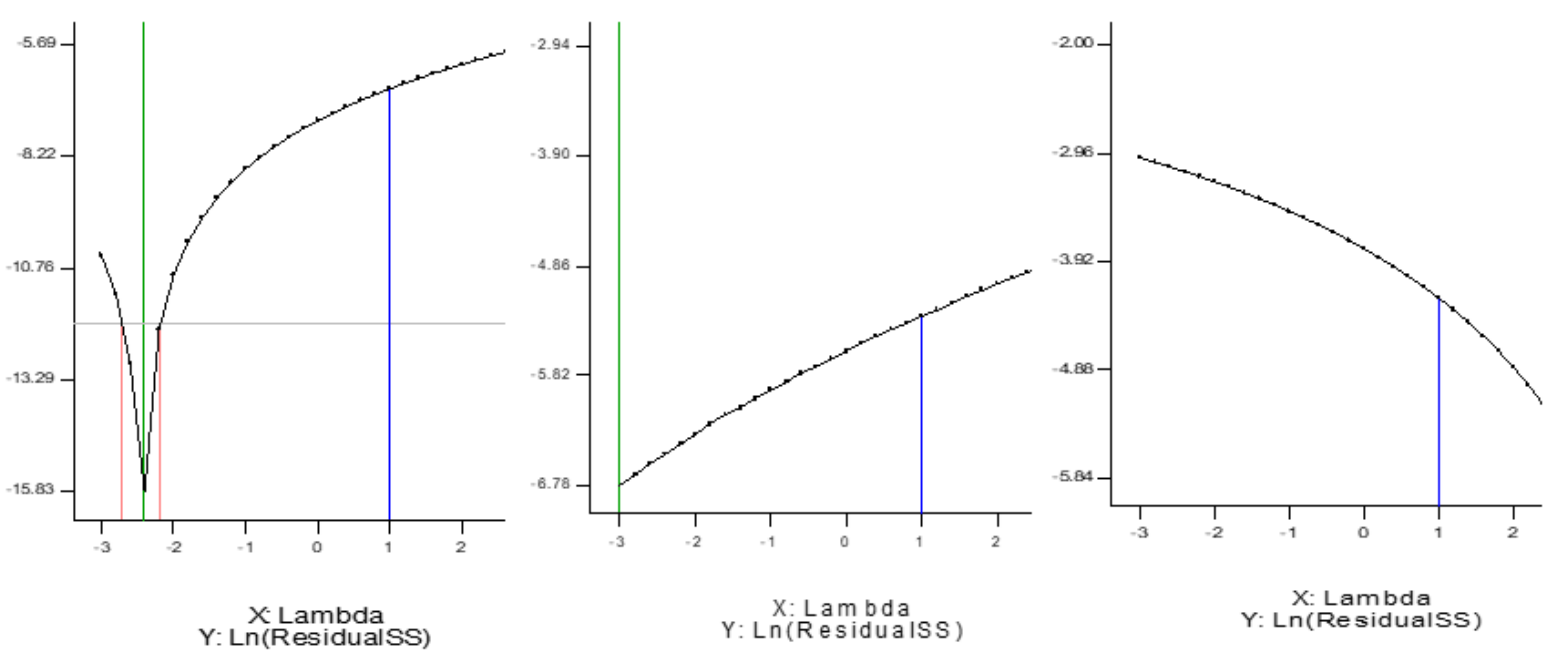

Figure 3

a: Predicted against Actual. b: Box-Cox Plot for Power Transformation 

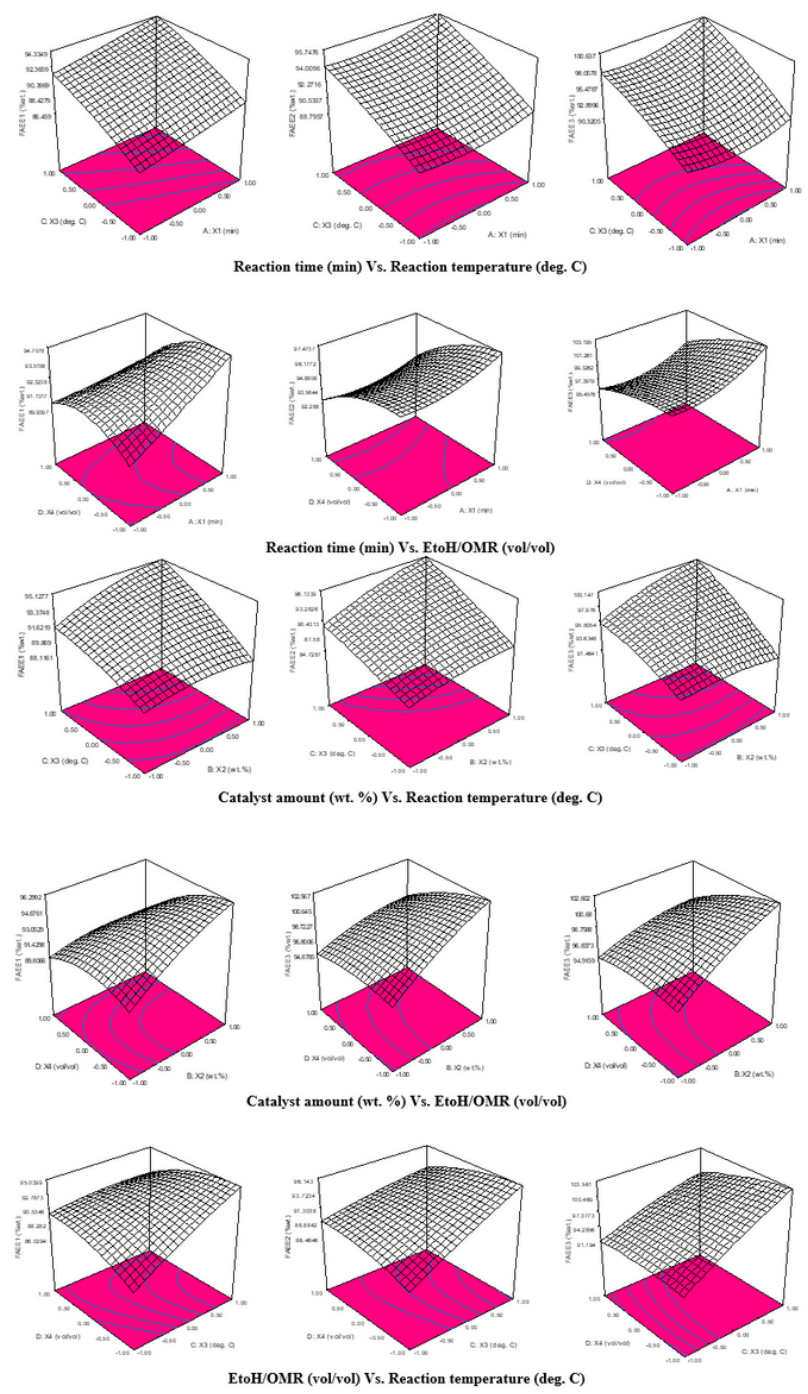

\section{Figure 4}

Three-dimensional contour plots showing the interaction of variables on the responses while keeping other factors constant 


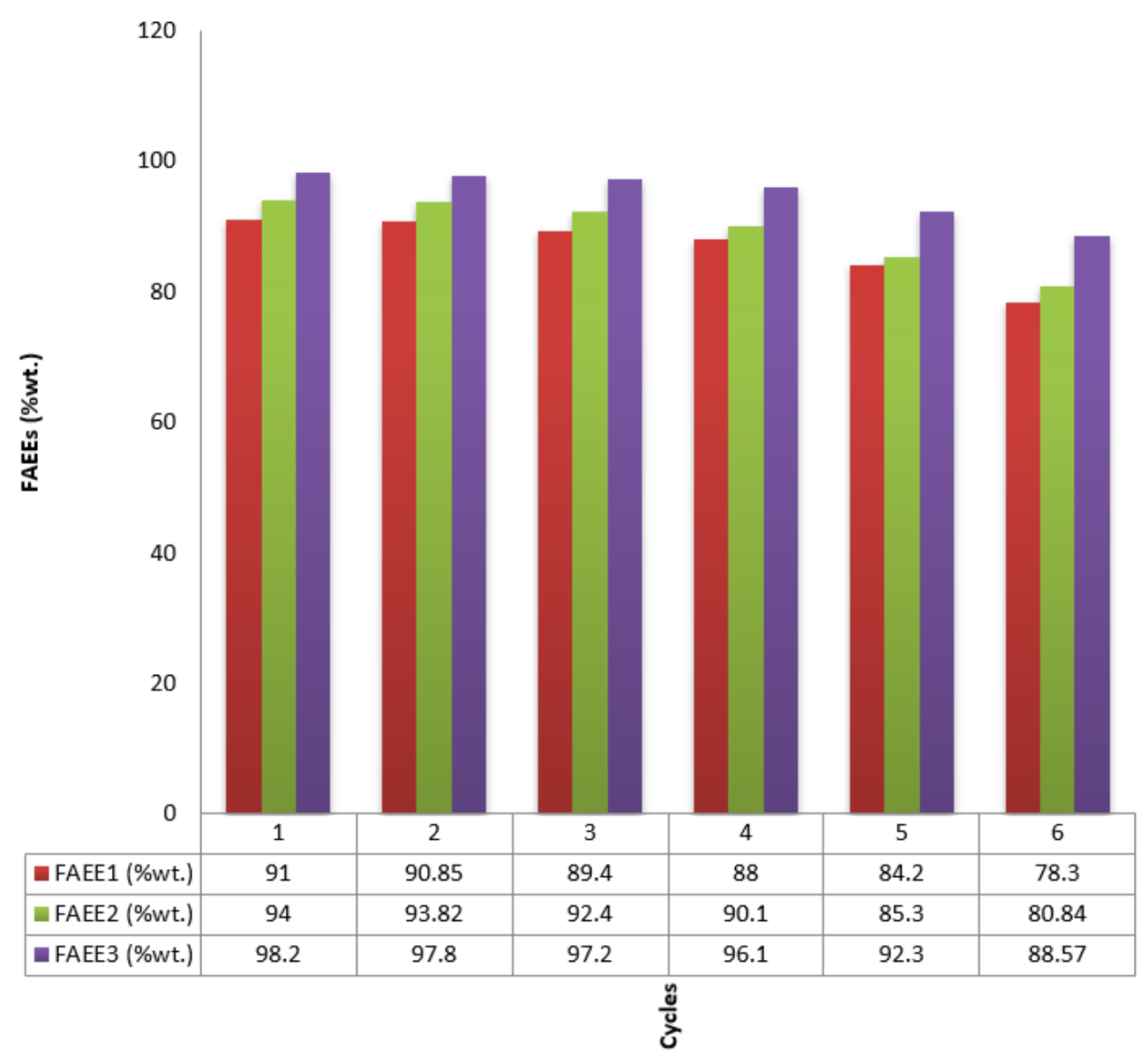

Figure 5

Plots of results of catalysts reusability test

\section{Supplementary Files}

This is a list of supplementary files associated with this preprint. Click to download.

- GraphicalAbstract.pdf

- Equations.pdf 